\section{Influence of surgical and chemical orchidectomy on weight and distribution of AChE-nerve fibres in thymuses of adult rats}

F. Dorko, D. Kluchová, A. Boleková, T. Špakovská, T. Borošová, K. Lovasová

Department of Anatomy, Faculty of Medicine, P.J. Šafárik University in Košice, Slovakia

\section{Abstract}

The thymus is a crossroad between the immune and neuroendocrine systems. As such, it is innervated by acetylcholinesterase (AChE)-positive fibres of the vagus, the recurrent laryngeal and the phrenic nerves. It is well know, that the innervations density of the thymus increases with age. In our study, adult rats were orchidectomized (surgically and chemically by the application of a luteinizing hormone-releasing hormone). The density of AChE-positive nerve fibres in thymuses, as well as the weight of thymuses was examined. The authors found that both surgical and chemical orchidectomy result in macroscopic and microscopic regeneration of the atrophied thymuses. In regenerated rat's thymuses after orchidectomy the density of AChE-positive nerve fibres was markedly higher in comparison with the control animals. The distribution, as well as the density of AChE-positive nerve fibres in regenerated thymuses after orchidectomy evokes the images of its innervations like in young animals before age-related involution. The authors also found a markedly higher weight of thymuses of orchidectomized rats in comparison with the control groups. In recent study the authors proved that after 8 weeks surgical orchidectomy leads to the regeneration of thymic AChE-positive innervation and chemical orchidectomy by administration of luteinizing hormone-releasing hormone after 4 weeks of adult rats.

\section{Introduction}

Thymus is a central organ of the immune system with an important endocrine function. It is a place where the $\mathrm{T}$ cells precursors proliferate and mature, these are responsible for the cell-mediated immunity. The thymus plays an important role in providing a suitable microenvironment for the proliferation, differentiation, TCR gene rearrangement and repertoire selection of T cells. ${ }^{1-4}$ The differentiation of $\mathrm{T}$ cells is a carefully orchestrated process. Mature and immunocompetent $\mathrm{T}$ cells leave the thymus through blood and lymphatic vessels and migrate to the peripheral lymphoid organs. ${ }^{5}$

From phylogenetical point of view, thymus played a key role in the evolution of animals during development of adaptive immune system; therefore it is an important element separating higher vertebrates from other animals. The development of thymus and $\mathrm{T}$ cells is a highly conserved process in vertebrates evolution. ${ }^{6-8}$ Human thymus grows rapidly in utero and reaches the biggest size compared to the body proportions during early postnatal period of babies. ${ }^{9-11}$ The highest immunological activity of the thymus is in the age of $6^{\text {th }}$ months after birth, when the thymus contains the highest overall numbers of thymocytes. ${ }^{12}$ After the 1st year of life, this organ starts to undergo changes, which become considerable in puberty and adulthood. The thymus undergoes a progressive reduction in size due to profound changes in its anatomy associated with loss of thymic epithelial cells and a decrease in thymopoiesis. These age-related changes in thymic structure are called physiological involution. ${ }^{13-18}$ It is assumed that involution of thymus plays the key role in immunity aging. ${ }^{19,20}$ Age-associated involution is reversible. For example, castration in old rats and mice results in the regeneration of the atrophied thymuses. ${ }^{21,22}$ During the prenatal and postnatal development thymus is sensitive to many environmental factors such as acute and chronic stress, malnutrition, infections or hormonal therapy. ${ }^{23,24}$ The term accidental involution was also implemented by Hammar in 1953 to describe striking regression in the size of thymus of younger individuals associated with malnutrition and infection. ${ }^{25}$

The thymus is a crossroad between the immune and neuroendocrine systems..$^{26}$ It has been hypothesized that maturational processes within the hypothalamo-pituitary-gonadal axis and thymus are reciprocally regulated via neural pathways. To test this hypothesis, the thymuses of adult rats after orchidectomy (surgical and chemical) were observed. The density of AChE-positive nerve fibres was examined by the method of enzyme histochemistry. We examined also the changes in thymic weight after orchidectomy.

\section{Materials and Methods}

Twenty-three male rats of strain Wistar, 12 months old (480-600 g) were used in the experiment. Ten rats were bilaterally orchidectomized under penthobarbital (Thiopental,
Correspondence: Prof. František Dorko, Department of Anatomy, Faculty of Medicine, P. J. Šafárik University in Košice, Šrobárova Street 2 , 04180 Košice, Slovakia.

Tel. +421.55.6428151 - Fax: +421.55.6428151.

E-mail: frantisek.dorko@upjs.sk

Key words: thymus, surgical and chemical orchidectomy, AChE-positive nerves, age-dependent involution, rat.

Received for publication: 24 December 2010. Accepted for publication: 15 May 2011.

This work is licensed under a Creative Commons Attribution NonCommercial 3.0 License (CC BYNC 3.0).

(C) Copyright F. Dorko et al., 2011

Licensee PAGEPress, Italy

European Journal of Histochemistry 2011; 55:e22 doi:10.4081/ejh.2011.e22

ICN a.s., Roztoky, Czech Republic) anaesthesia $(20 \mathrm{mg} / \mathrm{kg}$, i.p.). After the surgery the animals were kept seperately in cages under laboratory temperature. Preventively, we applied ATBAxetine (cefuroximum natricum, $40 \mathrm{mg} / \mathrm{kg}$ i.p., Medochemie Ltd., Limassol, Cyprus). We checked the surgical wounds every fifth day and on the fifth day we put the animals together into one cage, where they lived together for 8 to 10 weeks. Three rats were subjected to sham surgery ( $1^{\text {st }}$ control group). The control animals also underwent a sham surgery under penthobarbital anaesthesia. We opened the scrotum by longitudinal cuts and checked the placing of the testes. Then we sewed the wounds and put the animals into the same conditions as the experimental ones. Eight to ten weeks after the surgery/sham-surgery animals were euthanized by a lethal dose of thiopental.

Seven rats were injected with $0.25 \mathrm{~mL}$ luteinizing hormone-releasing hormone (LHRH) (Hoechst AG, Frankfurt am Main, Germany) - chemical orchidectomy. Three rats were administered with the same volume of vehicle ( $2^{\text {nd }}$ control group). Four weeks after the treatment both experimental and control animals were euthanized by lethal dose of thiopental. Same methods for experimental surgical and chemical orchidectomy were used by Fitzpatrick et al. ${ }^{27}$ and Greenstein et al. ${ }^{28}$ and in these cases the positive results were confirmed by measuring plasmatic levels of androgen hormones.

After preparation we weighed the thymuses of both surgically and chemically castrated rats, as well as the control individuals, and recorded these values into tables. Samples taken from the thymus were processed for demonstration of AChE-positive nerve fibres. During two hours the samples were fixed in 
$4 \%$ formaldehyde at the temperature of $4^{\circ} \mathrm{C}$. Sections were manufactured on freezing microtome thick $20 \mu \mathrm{m}$ and incubated in the incubation solution during the period of $2-4 \mathrm{~h}$ at the temperature of $37^{\circ} \mathrm{C}$. The incubation medium (according to method of El Badawi and Schenk) ${ }^{29}$ contained acetylthiocholine iodide needed for the visualization of specific AChE, tetraisopropylpyrophosphoramide (isoOMPA) for inhibition of non-specific AChE was used. The exact composition of incubation solution can be found in Table 1 , the final $\mathrm{pH}$ of solution was 5.6 to 6.0. Elaborated samples were assembled on slides and were examined under a light microscope JENALUNAR 2 (Zeiss, Jena, Germany). We visually assessed the density of the nerve fibres in thymuses of both experimental and control rats.

Differences in the thymic weight among four groups of rats were analyzed by Mann Whitney non-parametric test. We considered the results of the level of significance of $\mathrm{P}<0.05$ as statistically significant. Statistical calculations were done through the software Statistical Package for the Social Sciences (SPSS) for Windows version 13.0.

\section{Results}

It was found out that both surgical and chemical castration result in macroscopic (Figure 1) and microscopic regeneration of the atrophied thymuses. Thymuses of orchidectomized animals had typical bilobular shape with minimal quantity of adipose tissue in the organ. In the microscopic view the thymuses had thick cortex with an abundant number of lymphocytes (Figures 2 and 3). The thymuses in the $1^{\text {st }}$ and $2^{\text {nd }}$ control groups of the rats showed typical image of age-dependent involution. Parenchyma of the thymus is being replaced by adipose tissue. The microscopic image of the involuted thymus shows that the cortex of the lobules has become markedly thinner and having remarkable reduction of number of lymphocytes (Figure 4).

The weight of thymuses of experimental rats was quite different from the control group (Tables 2 and 3). The average weight of thymuses after surgical orchidectomy was 0.414 $\mathrm{g} \pm 0.058 \mathrm{~g}$ (relative thymic weight per $100 \mathrm{~g}$ body weight was $0.075 \pm 0.006$ ), in the 1 st control group this weight was $0.170 \mathrm{~g} \pm 0.010 \mathrm{~g}$ (relative thymic weight per $100 \mathrm{~g}$ body weight was $0.031 \pm 0.002$ ). The average weight of thymuses in rats after chemical orchidectomy was $0.370 \mathrm{~g} \pm 0.040 \mathrm{~g}$ (relative thymic weight per $100 \mathrm{~g}$ body weight was $0.066 \pm 0.005)$, in the $2^{\text {nd }}$ control group the thymic weight was 0.130 $\mathrm{g} \pm 0.025 \mathrm{~g}$ (relative thymic weight per $100 \mathrm{~g}$ body weight was $0.020 \pm 0.004$ ). Analysing dif- ferences in thymic weight, we discovered that rats after orchidectomy (surgical or chemical) reached statistically more significantly higher values of the thymic weight than control groups. The surgical orchidectomy caused pro-

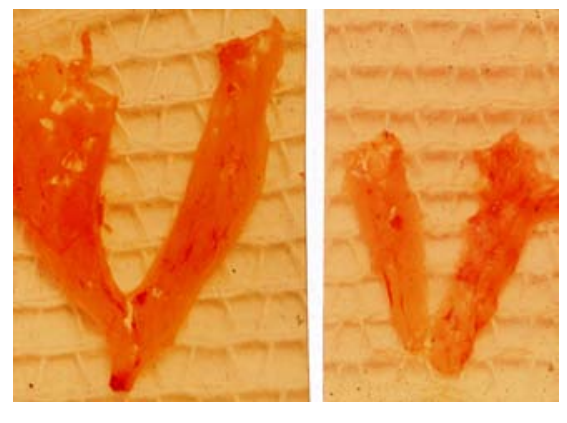

Figure 1. Macroscopic view on rats thymuses after orchidectomy (left side) and in control group (right side). nounced regeneration in thymic weight in comparison to chemical castration, but this difference is not significant.

The distribution as well as the density of AChE- positive nerve fibres in regenerated thy-

Table 1. The exact composition of incubation solution for the visualization of specific $\mathrm{AChE}$, according to $\mathrm{El} \mathrm{Badawi}$ and Schenk. ${ }^{29}$

\begin{tabular}{lc}
\hline Acetylthiocholine iodide & $12.5 \mathrm{mg}$ \\
Distilled water & $2.0 \mathrm{~mL}$ \\
\hline $0.82 \%$ Sodium acetate & $15.8 \mathrm{~mL}$ \\
$0.6 \%$ Acetic acid & $0.5 \mathrm{~mL}$ \\
\hline $2.94 \%$ Sodium citrate & $1.2 \mathrm{~mL}$ \\
$0.75 \%$ Copper sulphate & $2.5 \mathrm{~mL}$ \\
\hline
\end{tabular}

0.137\% Tetraisopropylpyrophosphoramide $0.5 \mathrm{~mL}$ $0.175 \%$ Potassium ferrocyanide $2.5 \mathrm{~mL}$

Table 2. Body weight of rats, weight of thymuses and relevant thymic weight after surgical orchidectomy and in the first control group.

\begin{tabular}{|c|c|c|c|c|}
\hline & No. & $\begin{array}{l}\text { Body weight } \\
\text { (g) }\end{array}$ & $\begin{array}{l}\text { Thymic weight } \\
\text { (g) }\end{array}$ & $\begin{array}{l}\text { Thymic weight per } \\
100 \mathrm{~g} \text { body weight }\end{array}$ \\
\hline Surgical orchidectomy & $\begin{array}{c}1 \\
2 \\
3 \\
4 \\
5 \\
6 \\
7 \\
8 \\
9 \\
10 \\
\text { Mean } \\
\text { SD }\end{array}$ & $\begin{array}{c}480 \\
510 \\
520 \\
540 \\
550 \\
550 \\
560 \\
590 \\
595 \\
600 \\
549.50 \\
39.048\end{array}$ & $\begin{array}{l}0.31 \\
0.35 \\
0.37 \\
0.40 \\
0.42 \\
0.45 \\
0.43 \\
0.44 \\
0.47 \\
0.50 \\
0.414 \\
0.058\end{array}$ & $\begin{array}{l}0.065 \\
0.069 \\
0.071 \\
0.074 \\
0.076 \\
0.082 \\
0.077 \\
0.075 \\
0.079 \\
0.083 \\
0.075 \\
0.006\end{array}$ \\
\hline $\begin{array}{l}\text { Control group } \\
\text { (sham-orchidectomized) }\end{array}$ & $\begin{array}{c}1 \\
2 \\
3 \\
\text { Mean } \\
\text { SD }\end{array}$ & $\begin{array}{c}510 \\
530 \\
580 \\
540.00 \\
36.056\end{array}$ & $\begin{array}{c}0.17 \\
0.16 \\
0.18 \\
0.170 \\
0.010\end{array}$ & $\begin{array}{l}0.033 \\
0.030 \\
0.031 \\
0.031 \\
0.002\end{array}$ \\
\hline
\end{tabular}

Table 3. Body weight of rats, weight of thymuses and relevant thymic weight after chemical orchidectomy and in the second control group.

\begin{tabular}{lcccc} 
& No. & $\begin{array}{c}\text { Body weight } \\
(\mathrm{g})\end{array}$ & $\begin{array}{c}\text { Thymic weight } \\
(\mathrm{g})\end{array}$ & $\begin{array}{c}\text { Thymic weight per } \\
\mathbf{1 0 0} \text { g body weight }\end{array}$ \\
Chemical orchidectomy & 1 & 530 & 0.32 & 0.060 \\
& 2 & 540 & 0.31 & 0.057 \\
& 3 & 550 & 0.37 & 0.067 \\
& 4 & 560 & 0.39 & 0.070 \\
& 5 & 575 & 0.41 & 0.071 \\
& 6 & 580 & 0.40 & 0.069 \\
Control group (rats & 7 & 590 & 0.39 & 0.066 \\
injected with vehicle) & 1 & 560.714 & 0.370 & 0.066 \\
& 2 & 530 & 0.10 & 0.019 \\
& 3 & 560 & 0.13 & 0.024 \\
& Mean & 545.00 & 0.15 & 0.027 \\
& SD & 15.000 & 0.130 & 0.020 \\
& & & 0.025 & 0.004 \\
\hline
\end{tabular}


muses after orchidectomy evokes the images of its innervations like in young animals before age-related involution (according to our previous study Dorko et al..$^{30}$ in female rats). AChE-positive nerves entered into the thymus accompanied with blood vessels as periarterial plexuses in connective tissue capsule. Further, they distributed along gradually ramifying arteries in interlobular septa. As dense, soft periarterial AChE-positive plexuses were found in the thymic medulla. Soft, single AChE-positive fibres came into the cortex of lobules of regenerated thymuses from following sources: subcapsular perivascular plexus- es, trabecular perivascular plexuses, trabecular AChE-positive fibres, perivascular medullar plexuses of thymus lobules (Figures 5, 6, 7, 8, 9 and 10).

On the other hand, in the control groups of the rats AChE-positive nervous components of the thymus were apparently represented less

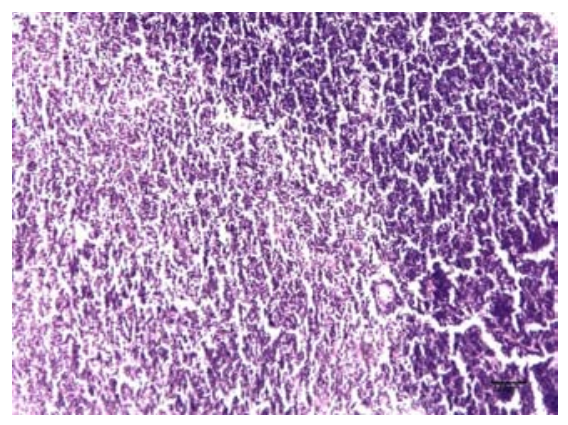

Figure 2. Thymus after surgical orchidectomy - regeneration of thymic parenchyma with well distinguished cortex (rich in lymphocytes) and medulla. Scale bar :50 $\mu \mathrm{m}$.

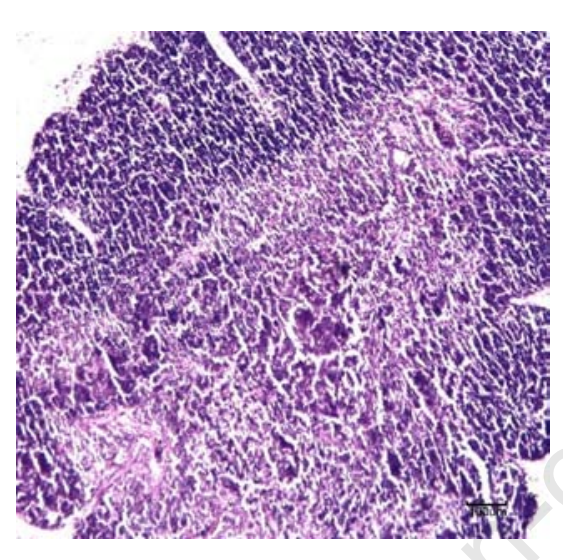

Figure 3. Thymus after chemical orchidectomy - regeneration of thymic parenchyma with well distinguished cortex (rich in lymphocytes) and medulla. Scale bar: $100 \mu \mathrm{m}$.

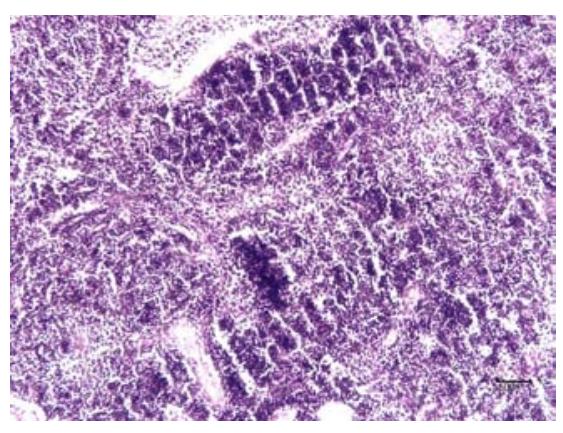

Figure 4. Thymus of rat from control group with same age as rats in Figures 2 and 3 (after age-related involution). The cortex is thinner and the difference between cortex and medulla is not clearly visible. Scale bar: $50 \mu \mathrm{m}$.

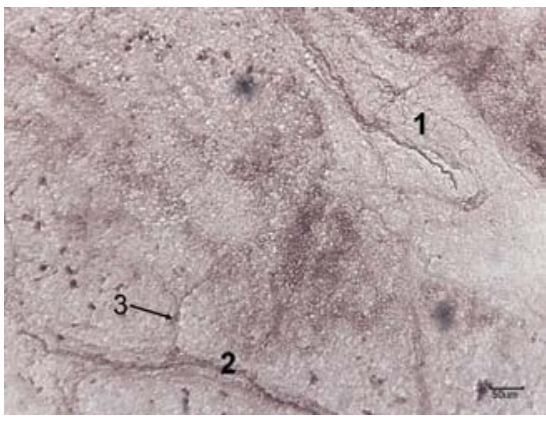

Figure 5. Thymus of rat after surgical orchidectomy. AChE-positive nerves entered into the thymus accompanied with blood vessels as periarterial plexuses in connective tissue capsule (1). AChE-positive nerve fiber in interlobular septum (2), which gradually ramifying into thymic parenchyma (3). Scale bar: $50 \mu \mathrm{m}$.

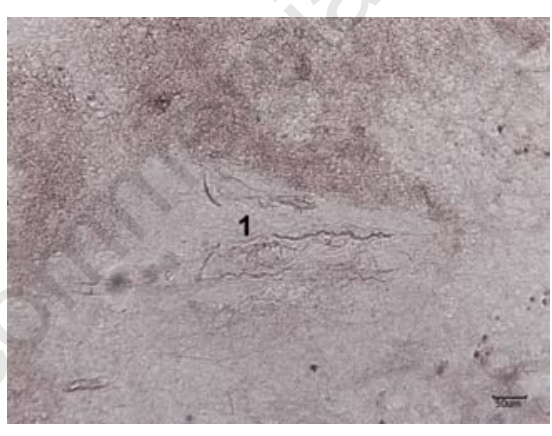

Figure 6. Thymus of rat after surgica orchidectomy. Plexus of AChE-positive nerves in interlobular septum (1). Scale bar: $\mathbf{5 0} \boldsymbol{\mu m}$.

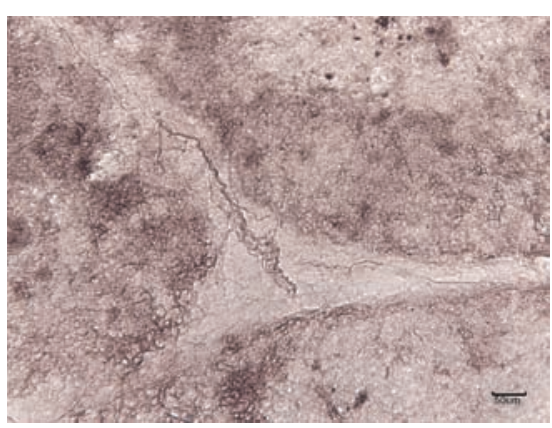

Figure 7. Thymus of rat after surgical orchidectomy. Periarterial and periarteriolar AChE-positive nerve plexuses. Nerve fibres detached from periarteriolar plexuses of the medulla penetrating the internal portion of the cortex of lobules. Scale bar: $50 \mu \mathrm{m}$.

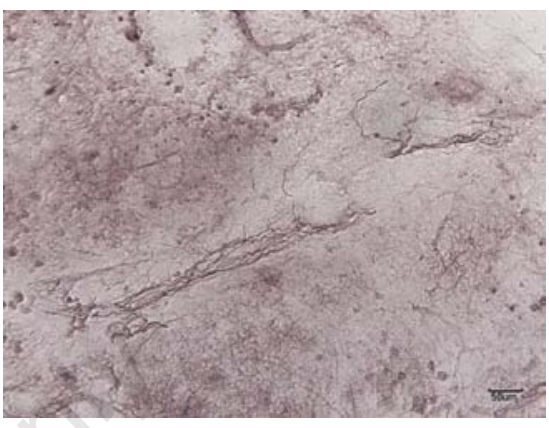

Figure 8. Thymus of rat after chemical orchidectomy. Abudant perivascular AChE- positive nerve plexuses in interlobular septum. Scale bar: $50 \mu \mathrm{m}$.

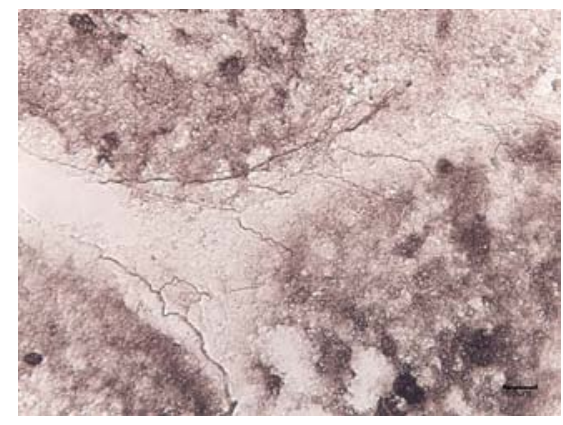

Figure 9. Thymus of rat after chemical orchidectomy. Solitary AChE- positive nerve fibres in interlobular septum penetrating into the cortex. Scale bar: $50 \mu \mathrm{m}$.

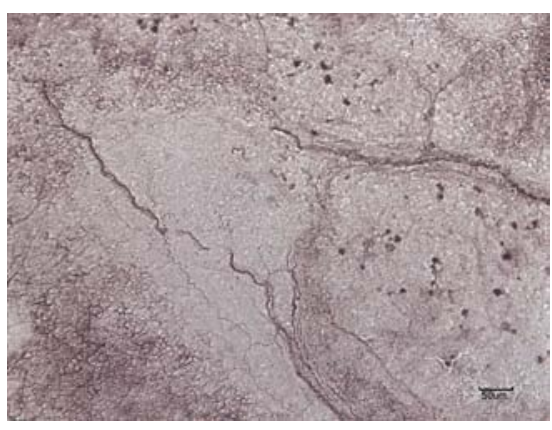

Figure 10. Thymus of rat after surgical orchidectomy. Periarterial and periarteriolar AChE-positive nerve plexuses. Nerve fibres detached from periarteriolar plexuses of the medulla penetrating the internal portion of the cortex of lobules. Scale bar: $50 \mu \mathrm{m}$. 
contrastively and in smaller density. Therefore it was possible to identify them only in perivascular spaces (Figures 11 and 12).

We found that the regeneration of the thymus after the surgical castration is well observed within 10 weeks after the surgery; whereas the chemical castration is (long-term dosage of LHRH) is distinct after 28 days of the administration of the hormone.

\section{Discussion}

Our results indicate that the weight of the thymus of middle-age rats increases after orchidectomy. Greenstein et al. ${ }^{28}$ induced first time in rats chemical orchidectomy by administration of LHRH. Regeneration of thymus after orchidectomy in old mice was observed also by Utsuyama and Hirokawa ${ }^{31}$ and Heng et $a l .{ }^{22}$ Regeneration of thymus of adult dogs after the administration of growth hormone was described by Monroe et al. ${ }^{32}$ After comparison of the present results to those obtained after ovariectomy (in our previous study, Dorko et $a l .{ }^{30}$ ) we can found pronounced regeneration in thymic size in males in comparison to females.

The thymus is innervated by AChE-positive

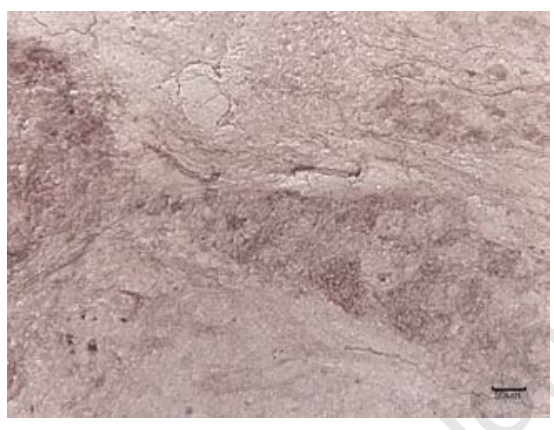

Figure 11. Thymus of adult rat from control group. Occasional poorly-visualised AChEpositive nerve fibres. Scale bar: $50 \mu \mathrm{m}$.

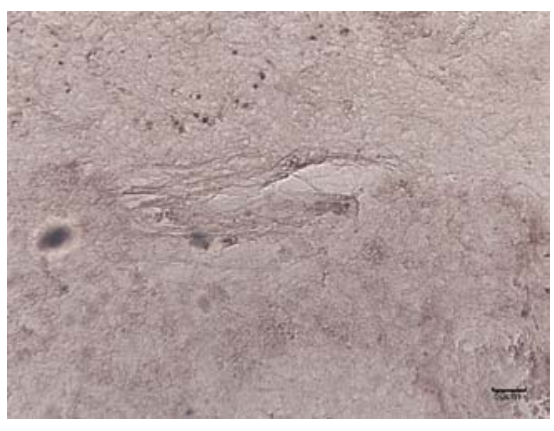

Figure 12. Thymus of adult rat from control group, without $\mathrm{AChE}$ - positivity of the nerve fibres. Scale bar: $50 \mu \mathrm{m}$. fibres of the vagus, the recurrent laryngeal and the phrenic nerves..$^{33}$ It is well known that the innervations density of the thymus increases with age, exceeding the reduction of thymic volume due to involution. The density of innervations correlates inversely with thymic volume. ${ }^{34}$ Our experiment shows that in regenerated thymuses of middle-age rats after orchidectomy the density of AChE-positive nerves is significantly higher in comparison with the control animals. While in involuted thymuses of control animals, AChE-positive nerves are localized in perivascular spaces, in experimental animals besides perivascular plexuses AChE-positive nerves are presented in functional parenchyma of regenerated thymuses in plenty. We assume that our findings represent indirect evidence that a cholinergic nerve stimulates lymphopoiesis in the thymus. The results of Leposavić et al. suggest that there is a critical period during ontogenesis when changes within the hypothalamo-pituitary-gonadal axis evoked by orchidectomy can affect the sympathetic nerve input to the rat thymus and therefore, most likely, development and function of the organ. ${ }^{35}$

Cavallotti et al. examined the occurrence and distribution of AChE activity in rats thymuses, too. ${ }^{36}$ They found specific AChE reactivity primarily in the arteries and, to a lesser extent, in the veins. Only a small amount of activity could be observed in association with the subcapsular and medullary part of the parenchyma and nerve fibres. After immunostimulation with interleukin beta in adult and aged rats they observed only small changes in AChE activity located in the walls of vessels, but they found significant modifications concern the parenchyma, the structures resembling nerve fibres and the whole thymus. The results about distribution and activity of AChE in immunostimulated adult rats are very similar to our results after orchidectomy.

The innervation of the thymus was studied in severe combined immunodeficient (SCID) mice. ${ }^{37}$ Only a few AChE-positive nerve fibres were observed in the SCID thymus, but 10 weeks after the transfer of bone marrow from normal mice into SCID mice was there any AChE reaction. This indicates that the innervations may be more important for the establishment of the microenvironment rather than the maintenance of lymphocytes differentiation.

\section{References}

1. Anderson G, Harman BC, Hare KJ, Jenkinson EJ. Microenvironmental regulation of $\mathrm{T}$ cell development in the thymus. Immunology 2000;12:457-64.

2. Staal FJT, Weerkamp F, Langerak AW,
Hendriks RW, Clevers HC. Transcriptional control of T lymphocyte differentiation. Stem Cells 2001;19:165-79.

3. Guyden JC, Pezzano M. Thymic nurse cells: a microenviroment for thymocyte development and selection. Int Rev Cytol 2003;223:1-37.

4. Laurent J, Bosco N, Marche PN, Ceredig R. New insight into the proliferation and differentiation of early mouse thymocytes. Int Immunol 2004;16:1069-80.

5. Kato S. Thymic microvascular system. Microsc Res Techn 1997;38:287-99.

6. Varga I, Pospíšilová V, Gmitterová K, Gálfiová P, Polák Š, Galbavý Š. The phylogenesis and ontogenesis of the human pharyngeal region focused on the thymus, parathyroid, and thyroid glands. Neuroendocrinol Lett 2008;29:837-45.

7. Bowden TJ, Cook P, Rombout JH. Development and function of the thymus in teleosts. Fish Shellfish Immunol 2005; 19:413-27.

8. Varga I, Pospisilova V, JablonskaMestanova V, Galfiova P, Polak S. The thymus: Picture review of human thymus prenatal development. Bratisl Lek Listy 2011;112:368-76.

9. Varga I, Pospisilova V, Jablonska V, Sisovsky V, Adamkov M, Galfiova P, et al. Thymic Hassall's bodies of children with congenital heart defects. Bratisl Lek Listy 2010;111:552-7.

10. Varga I, Tóth F, Uhrinová A, Neščáková E, Pospíšilová V, Polák Š. Anthropometry, nutrition status and thymic size of Gypsy newborns from Southwestern Slovakia. Bratisl Lek Listy 2009;110:354-7.

11. Varga I, Uhrinova A, Toth F, Mistinova J. Assessment of the thymic morphometry using ultrasound in full-term newborns. Surg Radiol Anat 2011; [Epub ahead of print].

12. Weerkamp F, De Haas EFE, Naber BAE, Comans-Bitter WM, Bogers AJJC, Van Dongen JJM, et al. Age related changes in cellular composition of the thymus in children. J Allergy Clin Immunol 2005;115:83440.

13. Nabarra B, Andrianarison I. Ultrastructural study of thymic microenviroment involution in aging mice. Exp Gerontol 1996;31:489-506.

14. Bodey B, Bodey BJr, Siegel S, Keiser HE. Involution of the mammalian thymus, one of the leading regulators of aging. In Vivo 1997;11:421-40.

15. Domínguez-Gerpe L, Rey-Méndez M. Evolution of the thymus size in response to physiological and random events throughout life. Microsc Res Tech 2003;62: 464-76.

16. Taub DD, Longo DL. Insights into thymic 
aging and regeneration. Immunol Rev 2005;205:72-93.

17. Cavallotti C, D’Andrea V, Tonnarini G, Cavallotti C, Bruzzone P. Age-related changes in the human thymis studied with scanning electron microscopy. Microsc Res Techn 2008;71:573-8.

18. Pospíšilová V, Varga I, Gálfiová P, Polák Š. Morphological view on human thymus ontogenesis. Čes-slov Pediat 2008;63:2018.

19. Kay MMB, Makinodan T. Immunology of ageing, evaluation of current status. Clin Immunol Immunopathol 1976;6:394-413.

20. Makinodan T, Kay MMB. Age influence on the immune system. Adv Immunol 1980; 29:287-330.

21. Fitzpatrik FTA, Kendall MD, Wheeler MJ, Adcock IM, Greenstein BD. Reappearance of thymus of ageing rats after orchidectomy. J Endokrin 1985;106:17-9.

22. Heng TS, Goldberg GL, Gray DH, Sutherland JS, Chidgey AP, Boyd RL. Effects of castration on thymocyte development in two different models of thymic involution. J Immunol 2005;175:2982-93.

23. Varga I, Pospíšilová V, Tóth F, Bevízová K, Polák Š. Factors affecting child thymus size and involution. Čes-slov Pediat 2008; 63:209-14.

24. Varga I, Tóth F, Uhrinová A, Neščáková E, Polák $\breve{S}$. Association among size of thymus, anthropometric dimensions and number of lymphocytes in peripheral blood in newborns from Slovakia. Biomed Pap Med Fac Univ Palacky Olomouc Czech Repub 2009;153:229-34.

25. Hammar JA. Konstitutionsanatomische studien úben die neurotisierung des Menschenembryos. IV. úber die innervationsverhaältnisse der inkretoorgane und der thymus bis den 4. Fötalmont. Z Mikroskop Anat Forsch 1953;38:253-92 [In German].

26. Geenen V, Brilot F. Role of the thymus in the development of tolerance and autoimmunity towards the neuroendocrine system. Ann N Y Acad Sci 2003;992:186-95.

27. Fitzpatrick FT, Kendall MD, Wheeler MJ, Adcock IM, Greenstein BD. Reappearance of thymus of ageing rats after orchidectomy. J Endocrinol 1985;106:R17-19.

28. Greenstein BD, Fitzpatrick FT, Kendall MD, Wheeler MJ. Regeneration of the thymus in old male rats treated with a stable analogue of LHRH. J Endocrinol 1987;112:34550 .

29. El Badawi A, Schenk E. Histochemical methods for separate, consecutive and simultaneous demonstrations of acetylcholinesterase and norepinephrine in cryostat sections. J Histochem Cytochem 1967;15:580-88.

30. Dorko F, Kocisová M, Gregor A, Schmidtová K, Bánovská E. Acetylcholinesterase-positive innervation of the thymus in old rats after ovariectomy. Bratisl Lek Listy 1996;97:298-300. [Article in Slovak].

31. Utsuyama M, Hirokawa K. Hypertrophy of the thymus and restoration of immune functions in mice and rats by gonadectomy. Mech Ageing Dev 1989;47:175-85.

32. Monroe WE, Roth JA, Grier RL, Arp LH, Naylor PH. Effects of growth hormone on the adult canine thymus. Thymus 1987; 9:173-87.

33. Bulloch K, Pomerantz W. Autonomic nervous system innervation of thymic-related lymphoid tissue in wildtype and nude mice. J Comp Neurol 1984;228:57-68.

34. Zirbes T, Novotny GE. Quantification of thymic innervation in juvenile and aged rats. Acta Anat (Basel) 1992;145:283-8.

35. Leposavić G, Ugresić N, Pejcić-Karapetrović B, Mićić M. Castration of sexually immature rats affects sympathetic innervation of the adult thymus. Neuroimmunomodulation 2000;7:59-67.

36. Cavallotti D, Artico M, Cavallotti C, Iannetti G, Frati A. Acetylcholinesterase activity in rat thymus after immunostimulation with interleukin beta. Ann Anat 2000;182:243-8

37. Mitchell B, Kendall M, Adam E, Schumacher U. Innervation of the thymus in normal and bone marrow reconstituted severe combined immunodeficient (SCID) mice. J Neuroimmunol 1997;75:19-27. 